\title{
Comparative Review of Aerobic and Anaerobic Composting for the Reduction of Organic Waste
}

\begin{abstract}
Composting is a self-heating, aerobic, bio-decomposition process of organic waste that has advantages over other disposal strategies since it reduces waste volume by $40-50 \%$ and kills pathogens by the heat generated during the thermophilic phase. This process uses organic waste (food scraps, grass chipping, etc.), water, soil (for added microbes) and either incorporation of air by turning the compost (aerobic) or lack of air within the compost (anaerobic). This study is designed to comparatively assess aerobic and anaerobic composting mechanisms on the productivity rate and analyse the different variables influencing the process. Based on the results obtained the time taken to completely compost the organic materials might not always be the same, because composting time is dependent on the percentage of microorganisms, water content, temperature and C:N ratio present in the pile at the said time along with the amount of material to be composted. Finally, this study will not only help farmers but also the general public in choosing a cost-effective and environmentally friendly way of reducing organic waste from landfills and reduction of greenhouse gases in the ozone layer.
\end{abstract}

Key words: Aerobic, Anaerobic, Composting, Landfill, Organic waste.

Available and arable land spaces decrease with a rapid increase in the human population over the years (UN, 2019; FAO et al. 2021). In countries like Afghanistan, Liberia, Niger and the Democratic Republic of Congo, the population is expected to increase threefold, while in Ethiopia, Nigeria and Yemen it is surging to double by the middle of this century (Walker, 2016). Moreover, even if we try to make do with the space that is here presently, survival may be hard if we do not properly dispose of our waste and try to reduce it to maximize land space and reduce the production of greenhouse gases (FAO et al. 2021). The increased population will lead to an enormous buildup of waste in landfills which will add to the increase in greenhouse gases in the atmosphere because of the organic materials that will be decomposing among the other solid waste found in the landfill (Höglund-Isaksson et al. 2020; Crippa et al. 2020; IPCC, 2021). Henceforth, an effective system to employ in the consumption of waste materials sustainable is to produce compost to enhance crop growth and development. Furthermore, the process will foster the principle to foster reducing, reusing and recycling wastes because if we do not it will help to occupy our already decreasing land space.

Urban waste generation began with human civilization and urbanization (Diaz and De Bertoldi, 2007). Globally, urbanisation promoted a paradigm shift in lifestyle and habits from nomadic hunters and gatherers to productive farmers and effective breeders of desirable livestock (Diaz and de Bertoldi, 2007). According to Diaz and de Bertoldi (2007), "the first waste pits was made out of stone and built outside the houses were found in Sumerian cities about 6000 years ago." Back then there was not as much waste as compared to now because of the population size. Currently, the world's population is approximately 7.7 billion people and yields
Department of Biology, University of Guyana, Georgetown, Guyana.

Corresponding Author: Abdullah Ansari, Department of Biology, University of Guyana, Georgetown, Guyana.

Email: abdullah.ansari@uog.edu.gy

How to cite this article: Mckenzie, I., Diana, S., Jaikishun, S. and Ansari, A. (2022). Comparative Review of Aerobic and Anaerobic Composting for the Reduction of Organic Waste. Agricultural Reviews. DOI: 10.18805/ag.R-191.

Submitted: 09-02-2021 Accepted: 09-12-2021 Online: 06-02-2022 approximately 3.5 million tons of waste daily or 1.3 billion tons annually, in which the developing countries account for about 54.02\% (UN, 2019; FAO et al. 2021; Adipah and Kwame, 2018). Interestingly, more than $50 \%$ of this comprises organic matter and hence composting can play an integral role in the diversification of its usage and rapidly alleviating existing pressure on landfills. Therefore, conserving landfill space and reducing the release of leachate and methane gas, which poses a threat to the ecosystem and environmental safety and contributes to about $5 \%$ of global greenhouse gas emissions (Amritha and Anilkumar, 2016; Zhang, 2019; IPCC, 2021). Gases emitted from landfills vary in composition with methane $\left(\mathrm{CH}_{4}\right)$ and carbon dioxide $\left(\mathrm{CO}_{2}\right)$ constituting 90 to $98 \%$, while nitrogen $(\mathrm{N})$, oxygen $\left(\mathrm{O}_{2}\right)$, ammonia $\mathrm{NH}_{4}{ }^{+}$), sulphides, hydrogen and various other gases make up the remaining 2 to $10 \%$ (Fig 1) (Zhang et al. 2019; Dodick and Kauffman, 2017; Takuwa et al. 2009). Some of these landfill gases result in adverse health effects for the general population residing within proximity (Takuwa et al., 2009). The quantity of greenhouse gas emissions from landfills is concomitant with landfill volume and age, climatic conditions of landfill sites, organic 
composition, the age of the waste, oxygen content, moisture content and temperature (Njoku et al. 2019; Zhang et al. 2019; Takuwa et al 2009). However, while these gases are being produced in one locale and then transferred to wider areas by permeating into the soil or by air and can seep into buildings through the air by windows, doors and ventilation systems. More so, exposure and inhalation to these gases can result in the prevalence of headache, difficulty breathing, coughing, eye irritation and nausea (Takuwa et al. 2009; Njoku et al. 2019). These gases can also cause serious illnesses and pose an elevated of gastrointestinal complications concomitant with the pathogens released from the sewage treatment plants including gastroenteritis, cryptosporidiosis, campylobacteriosis and serious respiratory complications which can lead to asthmatic response (Giusti, 2009; Sharma et al. 2018; Njoku et al. 2019). Hence, it is essential to reduce the use of landfill sites as means of decomposition and employ the alternative of composting which is environmentally friendly and sustainable. Instead of dumping organic wastes into landfills, these can be diverted to composting units where the products can be applied to plants to better growth and higher plant productivity (Fig 2).

Composting is a natural process of recycling that breaks down plant and other living materials and transforms them into an organic fertilizer that can be applied to the plants for better growth and high productivity It requires basic ingredients such as air, water, soil and microorganisms (Debertoldi et al. 1993). Compost enriches the soil with all the nutrients required for plant growth through mineralization, sustain soil moisture. Moreover, it is concomitant with suppressing plant pathology and pest infestations, providing a conducive environment for beneficial microorganisms and creating symbiotic associations with plant roots, (MeyerKohlstock et al. 2013; Favoino and Hogg, 2008). Biodegrading needs $65 \%$ moisture, while landfill materials contain approximately $25-30 \%$, thus the bio-degradation process is slow since adequate water is not supplied (MeyerKohlstock et al. 2013). Composting is one of the most effective methods of recycling to reduce organic waste from landfills. Composted products usage should be considered because they foster greater levels of carbon sequestration and hence provide insights into policy initiation and formation relative to climate change (Favoino and Hogg, 2008). As easy as composting sounds there is an art to it, which comes with different techniques, based on turning time (aeration). This paper will focus on two types of composting aerobic and anaerobic. Anaerobic composting takes almost no effort at all just place the materials in and water frequently. This paper reviews the literature on research comparing aerobic and anaerobic composting based on the different periods it takes to compost and analysing the different variables responsible.

\section{Aerobic and anaerobic composting}

Aerobic composting involves the introduction of air to break down the materials, this compost needs to be turned regularly, whether daily, twice a week or thrice a week. This

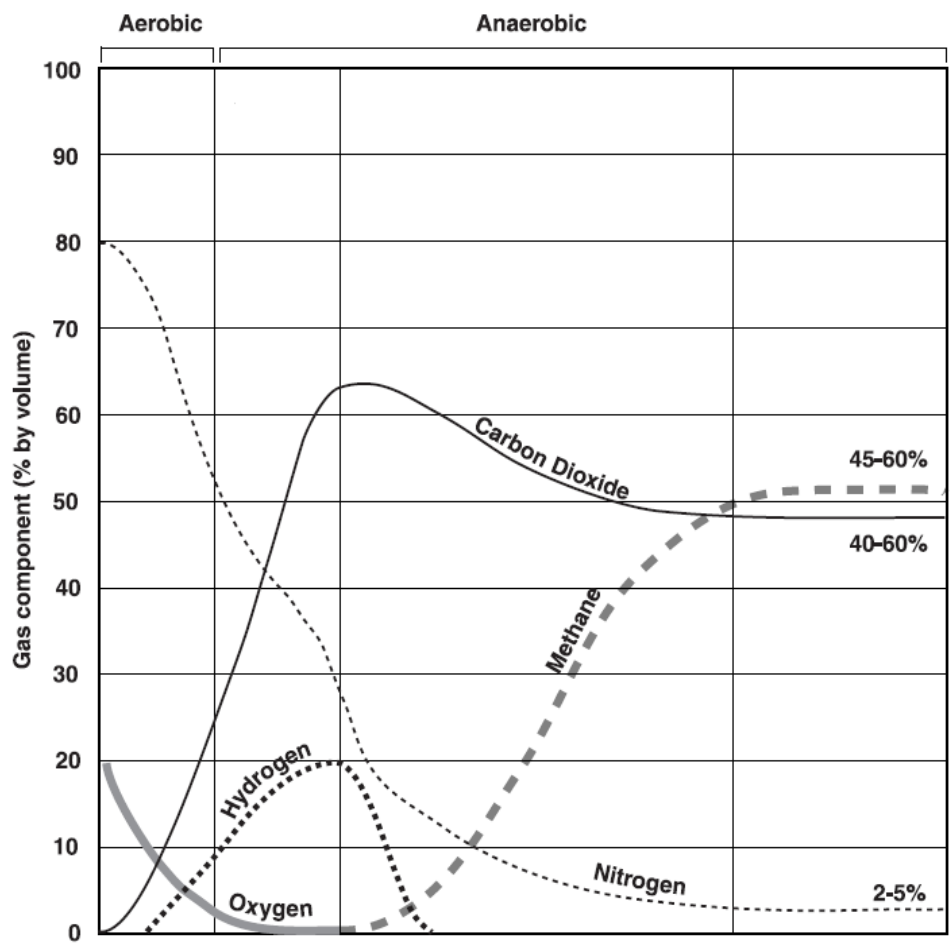

Fig 1: Gases released from landfills during aerobic and anaerobic respiration. Source: US EPA, 1997 and Maheshwari et al. 2015. 

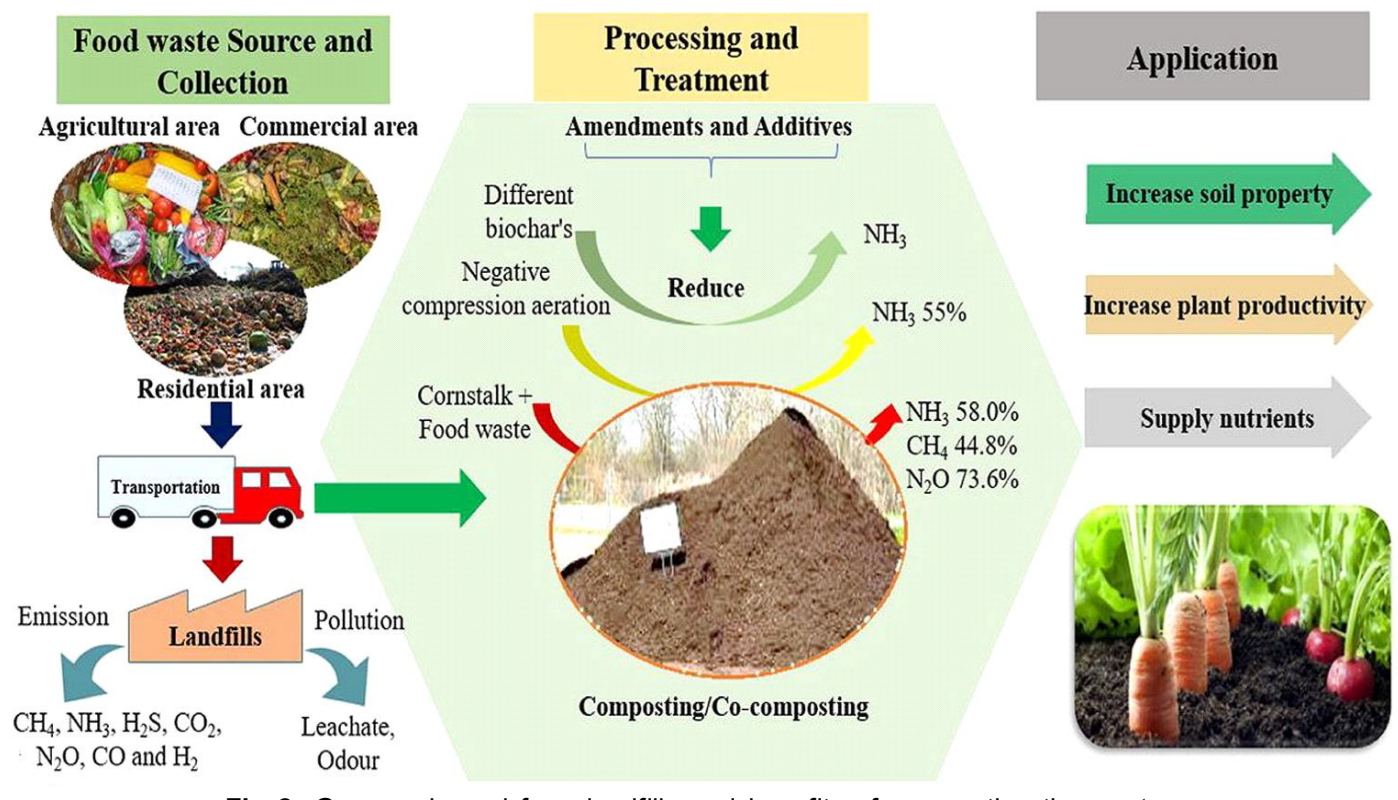

Fig 2: Gases released from landfills and benefits of composting the wastes.

(Source: Awasthi et al. 2020).

turning could be done with a tumbler composter for efficiency and reduced labour. However, plenty of green matter contains a significant amount of nitrogen. As the bacteria disintegrate the high-nitrogen-content materials, the temperature of the compost will increase resulting in increasing the rate of decomposition.

Anaerobic composting is slightly different from aerobic composting is does not require the incorporation of air, so it is less time-consuming. This involves leaving the materials in a compost heap of compost to decompose. Anaerobic composting entails placing the materials in a compost heap or composter and leave undisturbed until decomposition is completed. This compost will have a stench because of the different forms of bacteria present and the release of various substances during decomposition. This is what takes place in a landfill and it is not healthy because of the gases present.

Aerobic composting is the decomposition of organic matter using microorganisms that need oxygen to survive, aerobes. Contrastingly, anaerobic composting occurs with microorganisms that do not require oxygen to survive, anaerobes. In an anaerobic decomposition, most of the chemical energy contained in the starting substrate is released as methane gas (Swarthout, 1993). The process is characterized by very intense odours and lower heat is generation denotes decomposition takes longer and does not reach lethal temperatures to destroy the microorganism, weeds and seeds. To supersede these limitations, heat is added to the system. In anaerobic digestion, a sludge-like material is produced which seems to be more difficult to disintegrate. This sludge requires aerobic composting to complete the stabilization and decomposition. The heat produced in aerobic composting maintain the growth of beneficial bacteria including psychrophiles, mesophiles and thermophiles. However, turning can affect this process thereby can slow down the rate of composting. The microorganisms found in the compost establish an association that fosters the efficiency of the decomposition. The organic materials are consumed by the primary consumers (earthworm, bacteria such as actinomycetes and fungi) which are then consumed by the secondary consumers (beetle, mite, flatworm) and then consumed by the tertiary consumers (centipedes, ant, ground beetle) (Singh, 2012). The humus produced by composting contains a significant amount of fibre and inorganic nutrient composition including phosphorus, potassium and nitrogen and makes organic fertilizer that is beneficial to the ecosystem (Paul et al. 2019). Swarthout (1993) found that the microbes responsible for composting dwell in the moisture surrounding organic matter. Therefore, the right amount of moisture in compost can speed up the rate of decomposition which will increase the rate of microbes at the different phases of composting to quickly break down the organic materials. Thus, aerobic compost requires more moisture since turning will increase microbial activity and decrease moisture content rapidly while creating hot compost. Whereas, anaerobic compost does not require as much moisture as aerobic since it is a cold compost because of its slow decomposition.

\section{Carbon and nitrogen ratio}

Kale (1998) noted the composition of organic waste and posited that it constitutes two important elements, carbon (C) and nitrogen (N), which should be in the ratio 30:1. During the process of composting, the conditions become apposite for the growth and development of microbes. Fresh substrate high in $C$ (plant materials) should be combined with raw 
materials high in $\mathrm{N}$ (manure) will render the appropriate 30:1 ratio for ideal composting conditions (Awasthi et al. 2020; Dodick and Kauffman, 2017). More so, when the $C$ content is above 30 , heat production decreases thereby effectively reducing the rate of composting (Kale, 1998). Additionally, if the C: $\mathrm{N}$ ratio is $20: 1$ the $\mathrm{pH}$ will increase (loss of nitrogen as ammonia) creating untenable conditions for the functioning or can even result in the death of the microbes thereby halting the entire process. Oxygen is a prerequisite for aerobic composting and therefore avenue for its inclusion must be facilitated through proper aeration to enhance circulation within the composting materials (Alkoaik, 2019). Besides, an improper ventilation system will lead to insufficient oxygen resulting in anaerobic conditions and the production of unpleasant odours (Dickerson, 1999). Effective composting system must remain moist ranging between 40$60 \%$ that is adequate for the growth of microorganisms and sustain the microbial activity (Dickerson, 1999). Anaerobic compost contains higher levels of ammonium $\left(\mathrm{NH}_{4}{ }^{+}\right)$ because anaerobes tend to utilize less $\mathrm{N}$ than aerobes during decomposition (Awasthi et al. 2020; Dickerson, 1999). Composting anaerobically produces a significant volume of biogas (e.g. methane and carbon dioxide), which as a byproduct can be captured and used as a source of alternative energy adding value to it rather than releasing it into the atmosphere to further concentrate greenhouse gas accumulation. On the contrary, aerobic composting is more stable and the well-ordered decomposition and the speed of composting are reliant on the moisture, aeration and $\mathrm{C}: \mathrm{N}$ ratio of the heap.

\section{Temperature changes and microbial interactions}

Jeong and Kim, (2001) posited that temperature is integrally involved in the composting and also a determinant factor on the survival of the microbes and the completion of the process. As temperatures constantly fluctuate in the compost, it provides the right environment for different bacteria to have become more active. For example, psychrophilic, mesophilic and thermophilic bacteria operate best within specific temperature ranges. The psychrophiles function optimally at temperatures 0 and $13^{\circ} \mathrm{C}$ but can also be active at temperatures as low as $-18^{\circ} \mathrm{C}$. The heat generated makes provision for the growth of mesophiles that operate in temperatures between 15 and $40^{\circ} \mathrm{C}$ but thrive when temperatures are within the range of 21 to $32^{\circ} \mathrm{C}$. The heat generated by mesophiles increases the temperature in the heap, thus creating conditions suitable for the subsequent thermophilic bacteria to function. Thermophiles are initiated and start to function at temperatures around 40 to $45^{\circ} \mathrm{C}$ and will continue at the temperatures rise to about $70^{\circ} \mathrm{C}$, the optimal temperature when their population will decline. Constant turning of the heap provides sufficient aeration for maintaining the activity of thermophiles for a longer period. Decreasing temperatures result in the reduction of the thermophiles colony which indicates that the compost has reached some level of maturity. Mesophiles and psychrophiles will become active again at the reduced temperature and start to increase their populations at the periphery of the heap. The last stage of decomposition is done by Actinomycetes that produce antibiotics found in the compost and which inhibits the growth of bacteria. They release $\mathrm{C}$, nitrate $\left(\mathrm{NO}^{3-}\right)$ and $\mathrm{NH}_{4}^{+}$, resulting in the mineralization of nutrients to plants. Based on these papers aerobic composting is more suitable because most of the microbes depend on oxygen to break down the organic materials since the air will also contain other microbes and mixing will shuffle microbes to different places that they are needed. On the other hand, anaerobic composting heats up on its own based on the microbes present so the temperature is solely dependent on the activities of the microbes in the compost.

\section{CONCLUSION}

Globally, solid waste generated is contributing adversely to environmental pollution. Solid waste landfills are contaminated by heavy metals and gases and these can undoubtedly prove to be harmful to the ecosystem and some extend result in fatality. Moreover, implementing an environmentally friendly and sustainable system of disposing of solid waste is being trialled in many countries. Composting helps the environment by using organic waste and turning it into fertilizers, which can be used, in the agricultural industry. The two main methods of composting reviewed in this paper are Aerobic and Anaerobic. Aerobic composting works quickly but requires a high amount of maintenance, as the moisture and temperature need to be monitored closely along with the incorporation of air regularly. Even though the temperature is an important factor for composting, its effect is less influential than moisture content. Anaerobic composting does not need as much attention as aerobic as the microbes found in this compost does not need oxygen to survive. While anaerobic composting may be easier and less labour-intensive, because you do not need to turn the pile, than aerobic composting, it is smellier and takes a lot longer to produce usable compost compared to aerobic composting as the different types of microbes and organisms work at a much slower rate due mainly to the colder conditions. However, it is the surrounding environments and elements along with microbes that are available within the compost that determines the time of finished compost; this is so because microbes such as bacteria, fungi and other microorganisms need a suitable environment to degrade the organic materials.

\section{REFERENCES}

Adipah, S. and Kwame, O. (2018). A novel introduction of municipal solid waste management. Journal of Environmental Science and Public Health. 3:147-157

Alkoaik, F.N. (2019). Integrating aeration and rotation processes to accelerate composting of agricultural residues. PLoS ONE. 14(7): e0220343.

Amritha, P.K. and Anilkumar, P.P. (2016). Development of landscaped landfills using organic waste for sustainable urban waste management. Procedia Environmental Sciences. 35: 368-376. 
Awasthi, S.K., Sarsaiya, S., Awasthi, M.K., Liu, T., Zhao, J., Kumar, S. and Zhang, Z. (2020). Changes in global trends in food waste composting: Research Challenges and Opportunities, Bioresource Technology. 299.

Crippa, M., Solazzo, E., Huang, G., Huang, G., Guizzardi, D., Kofi, E., Muntean, M., Schieberle, C., Freidrich, R and Janessensmaenhout, G. (20200. High resolution temporal profiles in the Emissions Database for Global Atmospheric Research. Sci Data. 7: 121.

Debertoldi, M., Vallini, G. and Pera, A. (1983). The biology of composting: A review. Waste Management and Research. 1(2): 157-176.

De Bertoldi, M., Fenranti, M.P., L'Henmite, P. and Zueeoni, F. (1987). Compos!: Production, Quality and Use. Elsevier Applied Science, Landon, England.

Diaz, L.F. and de Bertoldi, M. (2007). Chapter 2 History of composting. Waste Management Series. 7-24.

Dickerson, G.W., (1999). Description and use of municipal solid waste composts in New Mexico. Circular 562. College of Agriculture and Home Economics New Mexico State University.

Dodick, J. and Kauffman, D. (2017). A Review of the European Union's Circular Economy Policy. Retrieved from R2PI Project.

FAO, IFAD, UNICEF, WFP and WHO. (2021). The State of Food Security and Nutrition in the World 2021. Transforming Food Systems for Food Security, Improved Nutrition and Affordable Healthy Diets for All. Rome, FAO.

Favoino, E. and Hogg, D. (2008). The potential role of compost in reducing greenhouse gases. Waste Management and Research. 26(1): 61-69.

Giusti, L. (2009). A review of waste management practices and their impact on human health. Waste Management. 29(8): 2227-2239.

Höglund-Isaksson, L., Gómez-Sanabria, A., Klimont, Z., Rafaj, P. and Wolfgang Schöpp, W. (2020). Technical potentials and costs for reducing global anthropogenic methane emissions in the 2050 timeframe-results from the GAINS model. Environ. Res. Commun. 2

IPCC. (2021): Summary for Policymakers. In: Climate Change 2021: The Physical Science Basis. Contribution of Working Group I to the Sixth Assessment Report of the Intergovernmental Panel on Climate Change [Masson-Delmotte, V., P. Zhai, A. Pirani, S. L. Connors, C. Péan, S. Berger, N. Caud, Y. Chen, L. Goldfarb, M. I. Gomis, M. Huang, K. Leitzell, E. Lonnoy, J.B.R. Matthews, T. K. Maycock, T. Waterfield,
O. Yelekçi, R. Yu and B. Zhou (eds.)]. Cambridge University Press. In Press.

Jeong, Y.K. and Kim, J.S. (2001). A new method for conservation of nitrogen in aerobic composting processes. Bioresource Technology. 79(2): 129-133.

Kale, R.D., (1998). Earthworm Cinderella of Organic Farming. Bangalore, India: Prism Book Pvt Ltd. pp: 88.

Maheshwari, R., Gupta, S. and Das, K., (2015). Impact of landfill waste on health: An overview. IOSR Journal of Environmental Science, Toxicology and Food Technology (IOSR-JESTFT). 1(4): 17-23.

Meyer-Kohlstock, D., Hädrich, G., Bidlingmaier, W. and Kraft, E. (2013). The value of composting in Germany- Economy, ecology and legislation. Waste Management. 33(3): 536539.

Njoku, P.O., Edokpayi, J.N. and Odiyo, J.O. (2019). Health and environmental risks of residents living close to a landfill: A case study of thohoyandou landfill, Limpopo Province, South Africa. International Journal of Environmental Research and Public Health. 16(12): 2125.

Paul, N., Giri, U. and Roy, G. (2019). Composting. In: Organic Fertilizers - History, Production and Applications.

Sharma, A., Gupta, A.K., Ganguly, R. (2018) Impact of open dumping of municipal solid waste on soil properties in mountainous region. J. Rock Mech. Geotechnical Eng. 10: 725-739.

Singh, R.P. (2012). Organic Fertilizers: Types, Production and Environmental impact. Nova Science Publishers.

Swarthout, F. (1993). The Science Of COMPOSTING: Become an aerobic instructor. The Science Teacher. 60(6): 26-29.

Takuwa, Y., Matsumoto, T., Oshita, K., Takaoka, M., Morisawa, S. and Takeda, N. (2009). Characterization of trace constituents in landfill gas and a comparison of sites in Asia. Journal of Material Cycles and Waste Management. 11(4): 305-311.

United Nations (UN), Department of Economic and Social Affairs, Population Division (2019). World Population Prospects 2019: Highlights (ST/ESA/SER.A/423).

United States Environmental Protection Agency (US EPA). (1997). Emission Factor Documentation for AP-42, Section 2.4, MSW Landfills. Research Triangle Park, NC, USA

Walker, R.J. (2016). Population growth and its implications for global security. American Journal of Economics and Sociology. 75(4): 980-1004.

Zhang, C., Xu, T., Feng, H. and Chen, S. (2019). Greenhouse gas emissions from landfills: A review and bibliometric analysis. Sustainability. 11(8): 2282. 